\title{
Comparison of nicotine chewing-gum and psychological treatments for dependent smokers
}

\author{
MARTIN RAW， M J JARVIS，C FEYERABEND， M A H RUSSELL
}

\section{Summary and conclusions}

The results of using nicotine chewing-gum to treat dependent smokers attending a withdrawal clinic were compared with the results of psychological treatment. At one-year follow-up $26(38 \%)$ out of 69 people who received nicotine gum were abstinent compared with seven $(14 \%)$ out of 49 who received psychological treatment $(p<0.01)$. Abstinence was confirmed by the measurement of carboxyhaemoglobin concentrations or expired air carbon monoxide. Blood nicotine concentrations when patients used the gum averaged half the smoking values, and side effects were few. Addiction occurred in only two subjects.

Thus nicotine chewing-gum is a useful aid to giving up smoking and is probably acceptable even for people with cardiovascular disease.

\section{Introduction}

Nicotine chewing-gum recently became available to doctors in Britain for use as an aid to giving up smoking. Trials so far have shown only modest advantages over placebo gum. ${ }^{1}$ The flavour of the gum has been improved, however, and clinical experience suggests that better results may be obtained when people use the gum for at least three months. During 1977-9 we tried to improve the success rate at our clinic by tailoring treatment methods (pharmacological or psychological) to our assessment of each smoker's problem-namely, pharmacological or psychological dependence. In the event we found ourselves giving pharmacological treatment (nicotine chewing-gum) to virtually all smokers. The results were encouraging, and we compare them here with the results of an earlier trial of psychological methods, ${ }^{2}$ which included an aversive method of rapid smoking for which high success rates have been claimed. ${ }^{34}$

\section{Subjects and methods}

All subjects were from the Maudsley Hospital smokers' clinic. The sample given psychological treatment $(n=49)$ was drawn from subjects attending the clinic during 1974-6 while those receiving nicotine chewing-gum $(n=69)$ attended during 1977-9. The same criteria for entry to the clinic were applied throughout both periods. Before treatment all subjects completed questionnaires about their smoking, attended an assessment interview, and returned a record of their normal smoking over 24 hours.

The 69 smokers who received the chewing-gum were drawn from an initial sample of 82 . Of the 13 excluded, seven were thought not to need the gum (five of these succeeded in stopping smoking). Two were excluded because of cardiovascular symptoms (neither stopped smoking), and four did not want to use the gum (two stopped). The two samples did not differ significantly in age, sex, or social class or in pre-

\footnotetext{
Addiction Research Unit, Institute of Psychiatry, Maudsley Hospital, London SE5

MARTIN RAW, BA, MPHIL, clinical psychologist

M J JARVIS, BSC, MPHIL, clinical psychologist

C FEYERABEND, BSC, biochemist

M A H RUSSELL, MRCP, FRCPSYCH, senior lecturer and consultant psychiatrist
}

treatment cigarette consumption, carboxyhaemoglobin concentration, or blood nicotine concentration (table I). Details of the psychological treatments are reported elsewhere. ${ }^{2}$ Subjects were seen in groups seven times during the first month. In the trial of nicotine gum subjects attended six times during the first month and thereafter less frequently, mainly to obtain gum. They were given $2 \mathrm{mg}$ nicotine gum to use as necessary, together with careful instructions on how to chew. ${ }^{1}$ In both studies subjects were followed up at three, six, and 12 months, and claims of abstinence at one-year follow-up were validated by measuring carboxyhaemoglobin concentrations or expired air carbon monoxide. ${ }^{5}$

TABLE I-Details of groups given psychological treatment or nicotine chewing-gum

\begin{tabular}{|c|c|c|}
\hline & $\begin{array}{l}\text { Psychological } \\
\text { treatment } \\
\left(n=49^{*}\right)\end{array}$ & $\begin{array}{l}\text { Nicotine } \\
\text { gum } \\
\left(n=69^{*}\right)\end{array}$ \\
\hline $\begin{array}{l}\text { Mean age (years) } \ldots \\
\text { Mean cigarette consumption (cigarettes/day) } \\
\text { Mean pretreatment carboxyhaemoglobin }(\%) \dagger \\
\text { Mean pretreatment blood nicotine }(\mathrm{nmol} / \mathrm{l}) \dagger \\
\text { No }(\%) \text { of men in group } \ldots \\
\text { No }(\%) \text { of subjects in social classes } \mathrm{I} \text { and } \mathrm{I} \text { II }\end{array}$ & $\begin{array}{l}39 \cdot 5 \\
34 \cdot 9 \\
8 \cdot 3 \\
213 \cdot 3 \\
20(41) \\
20(41)\end{array}$ & $\begin{array}{c}40 \cdot 7 \\
32 \cdot 3 \\
8 \cdot 3 \\
226 \cdot 3 \\
21(43) \\
25(51)\end{array}$ \\
\hline
\end{tabular}

None of the differences was statistically significant.

* Sample sizes for measurement of carboxyhaemoglobin concentration were $n=40$ (psychological treatment) and $\mathrm{n}=64$ (nicotine gum), and of nicotine concentration $\mathrm{n}=43$ and $\mathrm{n}=64$ respectively.

†Measured from venous blood sample taken two minutes after subjects had smoked a igarette.

Conversion: SI to traditional units-Nicotine: $1 \mathrm{nmol} / 1 \approx 0 \cdot 16 \mathrm{ng} / \mathrm{ml}$

\section{Results}

Outcome-Table II shows the most important results. Only eleven $(22 \%)$ of the subjects who received psychological treatment managed to stop smoking at one month compared with $41(59 \%)$ of those who received the nicotine gum $(p<0 \cdot 001)$. At one-year follow-up the success rate for psychological treatment had fallen to $14 \%$ compared with $38 \%$ in the group receiving nicotine gum $(\mathrm{p}<0.01)$.

TABLE II-Success rates over one year of follow-up. (Figures are numbers ( $\%$ ) of subjects abstinent)

\begin{tabular}{|c|c|c|c|c|c|c|c|}
\hline $\begin{array}{l}\text { Time from } \\
\text { start of } \\
\text { treatment }\end{array}$ & & & & & & $\begin{array}{l}\text { Psychological } \\
\text { treatment } \\
(\mathrm{n}=49)\end{array}$ & $\begin{array}{c}\text { Nicotine } \\
\text { gum } \\
(n=69)\end{array}$ \\
\hline $\begin{array}{l}\text { One month } \\
\text { Three months } \\
\text { Six months } \\
\text { One year }\end{array}$ & $\begin{array}{l}\because \\
\because \\
\cdots\end{array}$ & $\because$ & $\begin{array}{l}. \\
\because \\
\because\end{array}$ & $\begin{array}{l}\cdots \\
\cdots \\
\cdots\end{array}$ & $\begin{array}{l}. . \\
\because \\
\therefore\end{array}$ & $\begin{array}{r}11(22) \\
7(14) \\
7(14) \\
7(14)\end{array}$ & $\begin{array}{l}41(59) \\
35(51) \\
31(45) \\
26(38)\end{array}$ \\
\hline
\end{tabular}

All differences significant at $1 \%$ level ( $\chi^{2}$ test).

Quantity of gum used and duration of use-Fifteen of the 69 subjects gave up chewing the gum during the first week; only two of these succeeded in stopping smoking. The remaining 54 subjects were chewing an average of eight pieces of gum a day at one month. Altogether 54 subjects $(78 \%)$ stopped chewing the gum within three months. Of those who used it for more than three months, $10(67 \%)$ succeeded in stopping smoking. Only six people chewed the gum for more than one year, of whom four stopped using it within 18 months. In those who succeeded in stopping smoking there were significant correlations between duration of gum use and pretreatment blood nicotine concentration $(r=0.46, p<0.05, n=22)$ and carboxyhaemoglobin concentration $(r=0.48, p<0.05, n=22)$ but not cigarette consumption $(r=$ 0.33 , NS, $n=22$ ). Average daily consumption of gum at one month was related to the pretreatment blood nicotine concentration $(r=0.49$, 
$\mathrm{p}<0.05, \mathrm{n}=20$ ) but not to the carboxyhaemoglobin concentration $(\mathrm{r}=0.31$, NS, $\mathrm{n}=19)$ or cigarette consumption $(\mathrm{r}=0.09$, NS, $\mathrm{n}=22)$. Thus those with higher pretreatment blood nicotine concentrations chewed the gum for longer and chewed more of it.

Side effects-Only nine people $(13 \%)$ reported unpleasant side effects with the gum, and in only two cases did these cause them to give it up. Side effects reported were aching of the jaw (three subjects), mouth ulcers (three), slight nausea (two), and palpitations (one). In only one case were side effects cited as a reason for starting smoking again.

Blood nicotine concentrations in subjects using the gum-The mean plasma nicotine concentrations in the eight people for whom data were complete was $82 \mathrm{nmol} / 1(13.3 \mathrm{ng} / \mathrm{ml})$ when they were using the gum compared with $204 \mathrm{nmol} / 1(33.2 \mathrm{ng} / \mathrm{ml})$ when they were smoking cigarettes before treatment.

\section{Discussion}

The $38 \%$ success rate in people treated with nicotine chewinggum was more than double that obtained in similar smokers treated at the same clinic with psychological methods and is well above the range (about 15-25\%) reported for other methods. ${ }^{6}$ This improvement is unlikely to be due simply to secular trends in the propensity to give up smoking or to changes in the social climate, since the prevalence of smoking has not changed dramatically since the first study was done. Furthermore, the positive relation between pretreatment blood nicotine concentration and quantity and duration of gum use suggests that the presence of nicotine in the gum contributed to its success. Moreover, the incidence of side effects has been reduced since earlier studies. ${ }^{1}$

Most of these dependent smokers found the $2 \mathrm{mg}$ gum satisfactory, only six needing to change to the stronger, $4 \mathrm{mg}$, gum. Besides eliminating intake of tar, carbon monoxide, and other irritant gases, use of the gum gave rise to lower blood nicotine concentrations, which averaged less than half the smoking values.
This suggests that the gum is much safer than cigarette smoking and that cautious use would be acceptable even in those with cardiovascular disease who have failed to stop smoking with other methods. Nor is addiction to the gum a serious problem: only two $(3 \%)$ of our subjects were unable to give it up.

Finally, compared with other methods the gum is cost effective in terms of the therapist's time. It need take only a few minutes to prescribe the gum, instruct a smoker on how to use it, and record progress at follow-up visits. It is therefore a practical method for busy doctors.

We thank the Medical Research Council for financial support, A B Leo for supplying the nicotine gum, Brenda Bell for secretarial help, and Colin Taylor for statistical advice. Our colleagues Stephen Sutton and Robert Hallett gave helpful comments.

\section{References}

${ }^{1}$ Russell MAH, Raw M, Jarvis MJ. Clinical use of nicotine chewing-gum. Br Med F 1980;280:1599.

${ }^{2}$ Raw M, Russell MAH. Rapid smoking, cue exposure and support in the modification of smoking. Behav Res Ther (in press).

3 Schmahl DP, Lichtenstein E, Harris DE. Successful treatment of habitual smokers with warm smoky air and rapid smoking. $f$ Consult Clin Psychol 1972;36:105-11.

${ }^{4}$ Lichtenstein E, Harris DE, Birchler GR, Wahl JM, Schmahl DP. Comparison of rapid smoking, warm smoky air, and attention placebo in the modification of smoking behaviour. $\mathcal{f}$ Consult Clin Psychol 1973 40:92-8.

5 Jarvis MJ, Russell MAH, Saloojee Y. Expired air carbon monoxide: a simple and cost-effective breath test of tobacco smoke intake. $\mathrm{Br} \mathrm{Med} \mathcal{F}$ (in press).

${ }^{6}$ Raw M. The treatment of cigarette dependence. In: Israel Y, et al, eds. Research advances in alcohol and drug problems. Vol 4. New York: Plenum, 1978.

(Accepted 4 fuly 1980)

\section{SHORT REPORTS}

\section{Neonatal necrotising enterocolitis: comparative study in three large maternity hospitals}

In the past decade numerous American and British reports have confirmed an alarming increase in the incidence of neonatal necrotising enterocolitis. The incidence has been reported to be from $0.3 \%$ to $7.5 \%$ among infants admitted to neonatal intensive care units, rising to $27 \%$ in babies weighing less than 1200 g. $^{1}$ Because we seemed to be seeing far fewer cases than centres in Britain and America we designed a prospective study to determine the incidence in Dublin.

\section{Patients and results}

From September 1976 to August 1978 all infants with confirmed necrotising enterocolitis who had been born in maternity hospitals $A, B$ and $C$ were included in the study. The diagnostic criteria were the same in all three hospitals, consisting of clinical signs of abdominal distension, vomiting, blood in stools, and septicaemic appearance together with radiographic evidence of intramural gas, portal venous gas or pneumoperitoneum, or both, or by appearances at surgery or necropsy.

Fourteen neonates among the $\mathbf{4 2} 992$ babies born during the two-year period were diagnosed as having necrotising enterocolitis-an incidence of $0.03 \%$. Thirteen out of the 14 were born in hospital $\mathrm{A}$, only one was born in hospital B, and none was born in hospital C (table). The perinatal mortality rates for infants born in hospital A, B, and C in 1977 were $15.9,19 \cdot 4$, and 19.8 per 1000 live births. The 13 cases in hospital A were scattered throughout the period of study. Ten cases were diagnosed on clinical and radiological features, two at operation, and two at necropsy. Nine out of the 14 were boys and five were girls. Their gestational ages ranged from 29 to 41 weeks (mean 35.5): five were born at full term. Three weighed less than $1500 \mathrm{~g}$, six $1500-2500 \mathrm{~g}$, and five over $2500 \mathrm{~g}$ at birth. Five-minute apgar scores ranged from 7 to 10 . The age at which symptoms began ranged from 2 to 17 (mean 6.7) days. Pregnancy was complicated by hypertension in one case, antipartum haemorrhage in two, caesarean section in two, and prolonged

Incidence of neonatal necrotising enterocolitis (NEC) among total number of births in three maternity hospitals

\begin{tabular}{cccl}
\hline Hospital & $\begin{array}{c}\text { Cases of NEC } \\
\text { (No) }\end{array}$ & $\begin{array}{c}\text { Total births } \\
\text { (No) }\end{array}$ & $\%$ \\
\hline A & 13 & 14210 & $0 \cdot 1$ \\
B & 1 & 13463 & 0.008 \\
Total & 0 & 15319 & 0.03 \\
\hline
\end{tabular}

rupture of membrane in one. Neonatal complications included mild hyaline membrane disease in two babies, recurrent apnoea in four, jaundice in seven, patent ductus in five, umbilical vein catheterisation in two, and cardiac catheterisation in one. Four of the 14 infants had not been fed before the onset of necrotising enterocolitis, one was fed only clear fluids, eigh received SMA, and one Ostermilk feeds.

\section{Comment}

The most interesting point that emerges from this prospective study is the remarkably low overall incidence of necrotising enterocolitis and the striking difference in the incidence in three large maternity hospitals in Dublin. Three possible explanations may be offered for the difference in incidence. Firstly, an increased awareness of the disease in hospital A may have increased diagnostic accuracy. This 